\title{
Effects of a Novel Class III Antiarrhythmic Agent, NIP-142, on Canine Atrial Fibrillation and Flutter
}

\author{
Hidehiko Nagasawa, MD; Akira Fujiki, MD; Naoki Fujikura, BS*; \\ Tomoyuki Matsuda, MS*; Toru Yamashita, PhD*; Hiroshi Inoue, MD
}

\begin{abstract}
The effects of a new benzopyran derivative, NIP-142, on atrial fibrillation (AF) and flutter (AFL) and on electrophysiological variables were studied in the dog. NIP-142 $(3 \mathrm{mg} / \mathrm{kg})$ was administered intravenously to pentobarbital-anesthetized beagles during vagally-induced $\mathrm{AF}$ and during AFL induced after placement of an intercaval crush. Isolated canine atrial tissues were studied using standard microelectrode technique. NIP-142 terminated AF in 5 of 6 dogs after an increase in fibrillation cycle length (CL) and prevented reinitiation of AF in all 6 dogs. NIP-142 terminated AFL in all 6 dogs without any appreciable change in flutter CL, and prevented reinitiation of AFL in all 6 dogs. NIP-142 prolonged atrial effective refractory periods $(11 \pm 5 \%, 3 \pm 3 \%, 12 \pm 3 \%$, and $10 \pm 5 \%$ from the baseline value at basic CLs of $150,200,300$, and $350 \mathrm{~ms}$, respectively) without changes in intraatrial conduction time. The prolongation of the atrial effective refractory period was greater in the presence of vagal stimulation. NIP-142 decreased action potential phase-1 notch and increased phase- 2 plateau height without making any changes in the action potential duration, although it did reverse carbachol-induced shortening of the action potential duration. In conclusion, NIP-142 is effective in treating AFL and vagally-induced AF by prolonging atrial refractoriness. (Circ J 2002; 66: 185-191)
\end{abstract}

Key Words: Antiarrhythmic agent; Atrial fibrillation; Atrial flutter; NIP-142; Refractoriness

$\mathbf{M}$ ost class III drugs block the rapid component of the delayed rectifier current $(\mathrm{IKr})$, increase the action potential duration (APD) and prolong the QT interval, all of which can lead to torsades de pointes! In addition, the efficacy of $I \mathrm{Kr}$ blockers as treatment for tachyarrhythmias is limited because of the reverse use dependency of the class III effect; the effect on APD could be attenuated at shorter cycle lengths as seen in atrial fibrillation $(\mathrm{AF})$ ? For these reasons, the efforts in developing new class III antiarrhythmic drugs has been directed toward more effective compounds but with low proarrhythmic risk.

NIP-142 $\left(\left(3 R^{*}, 4 S^{*}\right)-4\right.$-cyclopropylamino-3, 4-dihydro-2, 2-dimethyl-6-(4-methoxyphenylacethylamino)-7-nitro- $2 \mathrm{H}$ 1-benzopyran-3-ol) is a newly developed benzopyran derivative (Fig 1), which terminates aconitine-induced atrial tachyarrhythmia in isolated guinea pig hearts and anesthetized canine hearts ${ }^{3}$ and binds to the bartrachotoxinsensitive $\mathrm{Na}^{+}$channel site 2 receptor to which aconitine binds, but not to the tetrodotoxin-sensitive $\mathrm{Na}^{+}$channel site 1 receptor. In anesthetized dogs, the drug decreases heart rate in spite of transient hypotension, and inhibits both Land T-type calcium currents $\left(I_{\mathrm{Ca}}\right)$ in isolated guinea pig ventricular myocytes. NIP-142 prolongs atrial but not ventricular refractoriness, does not prolong the QT interval ${ }^{3}$ and has little effect on the action potential variables5 A preliminary study suggests this new compound blocks the acetylcholine-activated potassium current $(\mathrm{I}, \mathrm{ACh})$ in the

(Received September 19, 2001; revised manuscript received November 2, 2001; accepted November 7, 2001)

The Second Department of Internal Medicine, Toyama Medical and Pharmaceutical University, Toyama, and *Biological Research Laboratories, Nissan Chemical Industries, Saitama, Japan

Mailing address: Hiroshi Inoue, MD, The Second Department of Internal Medicine, Toyama Medical and Pharmaceutical University, 2630 Sugitani, Toyama 930-0194, Japan dog, but does not bind to the muscarinic receptors expressed in Chinese hamster ovary cell (unpublished data), which further suggests that NIP-142 may be effective in terminating the $\mathrm{AF}$ caused by increased vagal tone without causing ventricular proarrhythmias. However, the effects of this drug on other types of atrial tachyarrhythmias and atrial action potential characteristics have not been explored thoroughly. We, therefore, investigated the effects of NIP142 on AF induced by vagal stimulation and on atrial flutter (AFL) caused by reentry induced by intercaval obstacle, as well as its effects on electrophysiological variables, in the dog. We also investigated its effects on the atrial action potential characteristics in isolated canine atrial tissue by using a standard microelectrode technique.

\section{Methods}

\section{Animal Preparation}

Thirty-three beagles (Kasho, Tokyo, Japan) of either sex weighing $10-17 \mathrm{~kg}$ were anesthetized with sodium pentobarbital $(25 \mathrm{mg} / \mathrm{kg}$, iv). Animal handling procedures were performed in accordance with the 'Guideline for Animal Experiment' at the university. Dogs were ventilated with room air via an endotracheal tube connected to a volume-

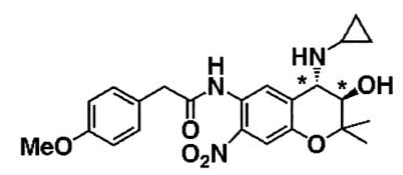

$\left(3 R^{\star}, 4 S^{\star}\right)$-4-cyclopropylamino-3,4-dihydro-2,2-dimethyl6-(4-methoxyphenylacethylamino)-7-nitro-2 $\mathrm{H}$-1-benzopyran-3-ol

Fig 1. Molecular structure of NIP-142. 
cycled respirator (607E, Harvard Apparatus, Millis, USA). A left femoral vein was cannulated to infuse $0.9 \%$ saline for replacement of spontaneous fluid losses and also to inject drugs. After median sternotomy, the heart was exposed and suspended in a pericardial cradle. The chest was kept warm by 2 operating lamps and covering it with a plastic sheet.

\section{Vagally Induced AF Model}

As in a previous report, 6 both vagus nerves were isolated in the neck of $6 \mathrm{dogs}$, ligated twice and then severed. Bipolar Teflon-coated stainless steel wire hook electrodes with $1.5-\mathrm{cm}$ non-coating distal ends were embedded through a 27-gauge needle within and parallel to the shaft of each vagus to stimulate the efferent vagal nerve. Both ansae subclaviae were isolated at the exit of the stellate ganglia, ligated twice and severed. Octapolar electrode catheters (electrode interval $2.5 \mathrm{~mm}$ ) were inserted into bilateral atrial appendages to record the atrial electrograms. A bipolar electrode (interelectrode distance $2 \mathrm{~mm}$ ) was sewn onto the epicardial surface of the right atrial free wall for stimulation. Atrial electrograms and electrocardiogram (ECG) lead II were recorded simultaneously on a thermal recorder (RTA-1200M, Nihon Kohden, Tokyo, Japan) at a paper speed of $100 \mathrm{~mm} / \mathrm{s}$ and stored in a digital data recorder (RD130TE, TEAC, Tokyo, Japan) for later analyses. An oscilloscope (VC-11, Nihon Kohden) was also used to monitor real time electrograms.

Stimulation of both the vagi was performed with separate isolated constant current sources (SS-202J, Nihon Kohden) driven by a programmable stimulator (SEN-7203, Nihon Kohden). The current strength was set to prolong sinus cycle length by $100 \%$ with right vagal stimulation and to produce a 2:1 atrioventricular (AV) block with left vagal stimulation by using $2-\mathrm{ms}$ rectangular pulses at $50 \mathrm{~Hz}$. In some dogs, left vagal stimulation produced complete AV block without producing the 2:1 block, and in these dogs, the current strength that produced complete AV block was used under ventricular backup pacing at 120 beats/min by a stimulator (DPS-1300D, Dia Medical System, Tokyo, Japan). Between interventions, the vagi were stimulated to ensure that the sinus and AV nodal responses remained constant.

During bilateral vagal stimulation, AF was induced by atrial extrastimulation using a digital programmable stimulator (SEC-2102, Nihon Kohden). AF lasting more than 10 min was repeatedly induced in each dog. Two minutes after

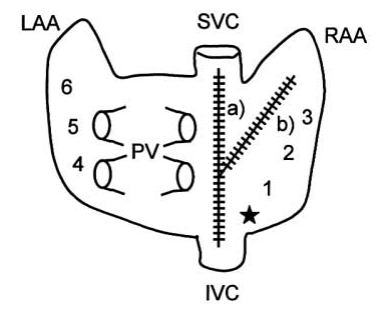

Fig 2. Diagram of the method used in the atrial flutter model. Atria are seen from the back, and the intercaval crush (a) between the superior (SVC) and inferior (IVC) venae cavae and (b) toward the right atrial appendage (RAA) is shown. Numbers indicate sites and numbers of recording electrodes corresponding to electrograms shown in Fig 4. A star indicates the site of the pacing electrode for programmed stimulation. LAA, left atrial appendage; PV, pulmonary veins. induction of AF, a bolus intravenous injection of NIP-142 $(3 \mathrm{mg} / \mathrm{kg}$ ) was given (this dosage was selected according to a previous report ${ }^{3}$ ). If $\mathrm{AF}$ terminated within $5 \mathrm{~min}$ of the injection, induction of $\mathrm{AF}$ was repeated 2-5 min later. If $\mathrm{AF}$ was sustained for more than $5 \mathrm{~min}$ after the injection, vagal stimulation was stopped in order to terminate $\mathrm{AF}$, and induction of $\mathrm{AF}$ was also repeated.

To determine the atrial cycle length (CL) during $\mathrm{AF}$, atrial electrograms of 30-s duration recorded from the right atrial appendage during AF were analyzed by fast Fourier transformation using a waveform analysis program (BIMUTAS II, Kissei Comtec, Tokyo, Japan). Each 30-s interval was divided into six 5-s segments and from an average of the maximal powers of fast Fourier transformation of 4 simultaneous recordings from consecutive bipolar electrodes, a fibrillation CL was obtained. Next, the fibrillation CL of 6 segments were then averaged to represent each dog. This analysis was made before and after administration of NIP142 during AF.

To analyze the possible mechanism of termination of vagally induced $\mathrm{AF}$, the atrial effective refractory period (ERP) was determined at a basic cycle length (BCL) of 200 $\mathrm{ms}$ before and during vagal stimulation, and repeated after injection of NIP-142 (see later).

\section{AFL With Anatomical Obstacle Model}

In 6 dogs, after the chest was opened through lateral thoracotomy at the fourth right intercostal space, an anatomical obstacle was produced by ligation of the intercaval atrial tissue according to the method of a previous study ${ }^{7}$ (Fig 2). If AFL was not induced with atrial pacing after placing one intercaval obstacle $(n=3)$, an additional obstacle was created toward the right atrial appendage. Multipolar electrodes were placed on the epicardial surface of both atria to record atrial electrograms. AFL was repeatedly induced by burst right atrial pacing at cycle lengths of $100-115 \mathrm{~ms}$. AFL was defined as a regular atrial rhythm at cycle lengths of $110-150 \mathrm{~ms}$, as in the previous study? This AFL could be terminated by atrial pacing. Six consecutive atrial cycle lengths were averaged to represent the flutter $\mathrm{CL}$ in each experiment.

After AFL was initiated, a 10-min period was allowed to elapse to ensure that AFL was sustained. NIP-142 was injected intravenously at a dose of $3 \mathrm{mg} / \mathrm{kg}$. If $\mathrm{AFL}$ was terminated within $5 \mathrm{~min}$ of the injection, initiation of AFL was attempted. Venous blood samples were obtained just after the termination of AFL to determine plasma drug concentrations.

\section{Measurements of Electrophysiological Variables}

Eleven beagles were used to determine the effects of NIP142 on electrophysiological variables. For this purpose, the vagi and sympathetic nerves were kept intact during the experiment. Two bipolar electrodes (interelectrode distance $2 \mathrm{~mm}$ ) were sewn onto the epicardial surface of the right atrial free wall and the right ventricle for stimulation, and another 2 bipolar hook electrodes with an interhook distance of $1 \mathrm{~mm}$ were inserted into the right and left atrial free walls to record atrial electrograms. The tip of an octapolar electrode catheter (interelectrode distance $2.5 \mathrm{~mm}$ ) was positioned at the noncoronary cusp of the aortic valve through the right carotid artery to record the His bundle potential. Atrial and ventricular electrograms and ECG lead II were recorded on a thermal recorder, and stored in a digital data recorder. 
Before and $10 \mathrm{~min}$ after administration of NIP-142 (3 $\mathrm{mg} / \mathrm{kg}$, bolus iv), the electrophysiological variables were determined. Programmed stimulation was performed with 2-ms rectangular pulses at twice the diastolic threshold using a digital programmable stimulator. The shortest $\mathrm{CL}$ of atrial pacing that maintained $1: 1$ atrial capture $(1: 1 \mathrm{SA})$ or $1: 1$ atrioventricular conduction $(1: 1 \mathrm{AV})$ was determined by shortening the pacing CL in $10-\mathrm{ms}$ steps. The conduction time (CT) between the right atrial stimulation and either the right (intraatrial CT) or the left (interatrial $\mathrm{CT}$ ) atrial potentials was determined at an atrial pacing cycle length of $150 \mathrm{~ms}$. Atrio-His (AH) and His-ventricular (HV) intervals were determined at an atrial pacing CL of $300 \mathrm{~ms}$. Atrial and ventricular ERPs were determined with the extrastimulus method. A train of 10 basic stimuli (S1) was followed by a premature extrastimulus (S2) that produced a propagated response. The S1S2 interval was shortened in steps of $2 \mathrm{~ms}$ until S2 failed to produce a propagated response. ERP was defined as the longest S1S2 interval at which S2 failed to produce a propagated response. Measurements were repeated to ascertain the reproducibility of ERP. BCLs ranged from 150 to $350 \mathrm{~ms}$ to determine the use-dependency of effects of the test drug on ERP.

\section{In Vitro Experiments}

Ten beagles were killed by venesection under deep anesthesia induced by intravenous injection of an overdose of sodium pentobarbital. The right atrial muscles were dissected and isolated from adherent fat and connective tissues. The preparations were pinned to the silicon block in an organ bath, superfused continuously with physiologic salt solution equilibrated with $95 \% \mathrm{O}_{2}$ and $5 \% \mathrm{CO}_{2}$, and maintained at $36.5 \pm 0.5^{\circ} \mathrm{C}$. The preparations were stimulated with a programmable stimulator (SEN-3301, Nihon Kohden) at a constant frequency of $1.0 \mathrm{~Hz}$ by rectangular 3 -ms pulses delivered through a pair of bipolar platinum electrodes. Output was set at 1.5 times the diastolic threshold voltage. Transmembrane action potentials were recorded by a conventional technique with glass microelectrodes. The bath solution contained $118.4 \mathrm{mmol} / \mathrm{L} \mathrm{NaCl}, 4.7 \mathrm{mmol} / \mathrm{L} \mathrm{KCl}, 2.5$ $\mathrm{mmol} / \mathrm{L} \mathrm{CaCl}_{2}, 1.2 \mathrm{mmol} / \mathrm{L} \mathrm{MgSO}_{4}, 1.2 \mathrm{mmol} / \mathrm{L} \mathrm{KH}_{2} \mathrm{PO}_{4}$, $25.0 \mathrm{mmol} / \mathrm{L} \mathrm{NaHCO}$, and $11.1 \mathrm{mmol} / \mathrm{L}$ glucose $(\mathrm{pH}$ adjusted to 7.4 at $37^{\circ} \mathrm{C}$ ). The internal glass electrode solution contained $3 \mathrm{~mol} / \mathrm{L} \mathrm{KCl}$.

Action potentials were amplified by an amplifier (Intra 767, World Precision Instruments, Sarasota, USA), AD converted, and recorded in a computer (PC8901 DA, NEC, Tokyo, Japan). Data were analyzed by an analysis program (CAPA, Physio-Tech, Tokyo, Japan). The maximal upstroke velocity of the action potential (dV/dt max) was determined by an electronic differentiator. After an equilibration time of $60 \mathrm{~min}$ or more, the baseline evoked action potentials were recorded in 6 beagles. Then $0.3 \mu \mathrm{mol} / \mathrm{L}$ carbachol, a muscarinic receptor agonist, was added to the solution to shorten the APD. After $10 \mathrm{~min}$, when the APD became stable, NIP-142 was added cumulatively $(1,10$ and 100 $\mu \mathrm{mol} / \mathrm{L}$ ). In another 4 beagles, as a control study, the APDs were determined before and after application of NIP-142 $(1,10$ and $100 \mu \mathrm{mol} / \mathrm{L})$ without carbachol. The APDs were determined at 20\% (APD20), 50\% (APD50) and 90\% (APD90) of repolarization.

\section{In Vivo Solutions}

For the in vivo experiments, NIP-142 $(60 \mathrm{mg})$ was dissolved in $1 \mathrm{ml}$ of a solvent (polyethylene glycol 400 :

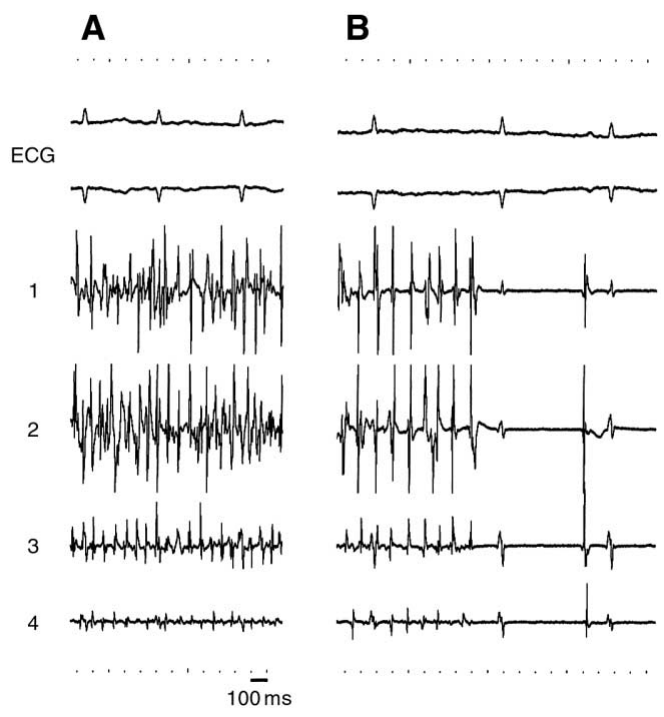

Fig 3. A representative example of termination of atrial fibrillation with NIP-142. Electrocardiogram (ECG) leads II and III, and atrial electrograms recorded from 4 right atrial sites are arranged from top to bottom. (A) Baseline atrial fibrillation before drug injection (B) Termination of atrial fibrillation. Before termination of atrial fibrillation with NIP-142, the fibrillation cycle length became longer at each recording site as compared with the baseline recording. RR intervals were also prolonged by NIP-142 before termination of atrial fibrillation.

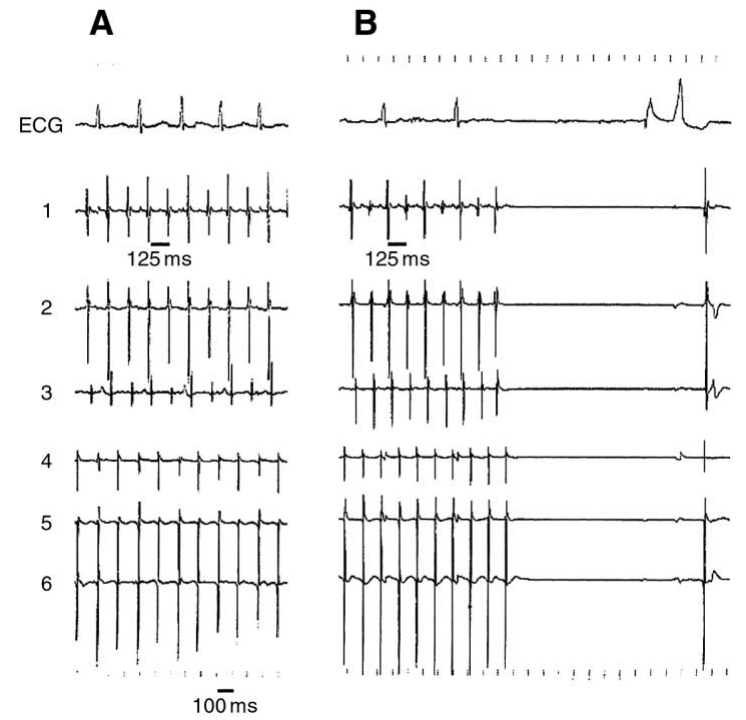

Fig 4. A representative example of termination of atrial flutter with NIP-142. Electrocardiogram (ECG) lead II and atrial electrograms recorded from 6 atrial sites are arranged from top to bottom. (A) Baseline atrial flutter before drug injection. (B) Termination of atrial flutter with NIP-142. NIP-142 did not change the flutter cycle length.

ethanol: $1 \mathrm{~mol} / \mathrm{L} \mathrm{HCl}=2: 3: 5$ ). The concentration of the solvent $(0.05 \mathrm{ml} / \mathrm{kg})$ had no influence on the electrophysiological variables. Neither AFL nor AF was terminated by an injection of this concentration of the solvent in our preliminary study.

\section{Data Analysis}

Results are presented as mean \pm SEM. The analysis of data for significance was performed by an analysis of vari- 
Table 1 Electrophysiological Effects of NIP-142

\begin{tabular}{|c|c|c|c|c|}
\hline & $n$ & Baseline & $N I P-142$ & $p$ value \\
\hline \multicolumn{5}{|l|}{ Atrial ERP (ms) } \\
\hline$B C L 150 \mathrm{~ms}$ & 11 & $95 \pm 4$ & $104 \pm 4$ & 0.032 \\
\hline BCL $200 \mathrm{~ms}$ & 11 & $116 \pm 4$ & $120 \pm 5$ & 0.189 \\
\hline BCL $300 \mathrm{~ms}$ & 11 & $126 \pm 4$ & $140 \pm 5$ & 0.002 \\
\hline$B C L 350 \mathrm{~ms}$ & 6 & $145 \pm 9$ & $157 \pm 7$ & 0.073 \\
\hline \multicolumn{5}{|l|}{ Ventricular ERP $(\mathrm{ms})$} \\
\hline BCL $200 \mathrm{~ms}$ & 10 & $142 \pm 4$ & $142 \pm 6$ & 0.466 \\
\hline$B C L 250 \mathrm{~ms}$ & 10 & $157 \pm 5$ & $161 \pm 5$ & 0.018 \\
\hline$B C L 300 \mathrm{~ms}$ & 10 & $169 \pm 6$ & $175 \pm 7$ & 0.025 \\
\hline$B C L 350 \mathrm{~ms}$ & 3 & $178 \pm 8$ & $180 \pm 13$ & 0.404 \\
\hline 1:1 SA (ms) & 9 & $121 \pm 5$ & $132 \pm 5$ & $<0.001$ \\
\hline $1: 1 \mathrm{AV}(\mathrm{ms})$ & 9 & $224 \pm 9$ & $264 \pm 6$ & $<0.001$ \\
\hline Intraatrial CT (ms) & 5 & $20 \pm 4$ & $20 \pm 4$ & $N S$ \\
\hline Interatrial CT (ms) & 5 & $38 \pm 1$ & $38 \pm 1$ & NS \\
\hline$A H(m s)$ & 5 & $85 \pm 7$ & $116 \pm 12$ & 0.004 \\
\hline$H V(m s)$ & 5 & $27 \pm 3$ & $27 \pm 3$ & $N S$ \\
\hline
\end{tabular}

Data expressed as mean values $\pm S E M$. ERP, effective refractory period; BCL, basic cycle length; $1: 1$ SA, the shortest atrial pacing cycle length that maintained 1:1 atrial capture; 1:1 AV, the shortest atrial cycle length that maintained 1:1 atrioventricular conduction; CT, conduction time (BCL $150 \mathrm{~ms}$ ); AH, the interval between the atrial potential and the His bundle potential (BCL $300 \mathrm{~ms}$ ); $H V$, the interval between the His bundle and the ventricular potential (BCL $300 \mathrm{~ms}$ ). In some dogs atrial and ventricular ERPs were not determined at longer $B C L$ because their sinus cycle lengths were shorter than $350 \mathrm{~ms}$.

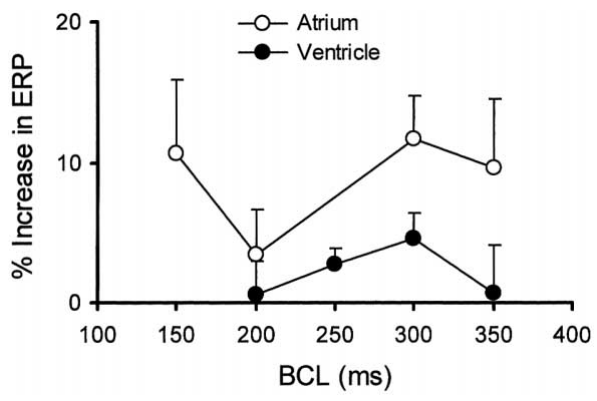

Fig 5. Relationships between basic cycle length (BCL) and NIP-142induced changes in atrial (open circles) and ventricular (solid circles) effective refractory periods (ERP). Data expressed as mean values \pm SEM. NIP-142-induced prolongation of ERP showed reverse usedependency at BCLs between 300 and $200 \mathrm{~ms}$ in the atrium as well as in the ventricle. At a BCL of $200 \mathrm{~ms}$, NIP-142 did not significantly change either atrial or ventricular ERPs. However, NIP-142 prolonged atrial ERP at the shortest BCL $(150 \mathrm{~ms})$.

ance and multiple comparisons were tested by Bonferroni's test. Mean values of 2 groups were compared by Student's t-test. Statistical significance was set at $\mathrm{p}<0.05$.

\section{Results}

\section{Effects on $A F$ and $A F L$}

$\mathrm{AF}$ was terminated in 5 of 6 dogs $283 \pm 50 \mathrm{~s}$ after bolus injection of NIP-142 (Fig 3). NIP-142 increased the mean fibrillation CL from $99 \pm 10$ (baseline) to $132 \pm 10 \mathrm{~ms}$ (just before termination, $\mathrm{p}<0.01)$. After termination of $\mathrm{AF}$ with NIP-142, sustained AF ( $>10 \mathrm{~s}$ ) was not able to be induced in any of the 6 dogs.

AFL was terminated with NIP-142 in all 6 dogs in $77 \pm 7 \mathrm{~s}$ (Fig 4). NIP-142 did not change flutter CL (from 126 \pm 4 to $128 \pm 4 \mathrm{~ms}$ just before termination of AFL). In 2 dogs, AFL degenerated into AF before termination. After drug administration AFL was not inducible in any of the 6 dogs. The plasma concentration of NIP-142 just after termination of AFL was $1.70 \pm 0.71 \mu \mathrm{g} / \mathrm{ml}$.

\section{In Vivo Electrophysiological Determination}

The electrophysiological effects of NIP-142 at different BCLs are detailed in Table 1. The relationships between $\mathrm{BCL}$ and drug-induced changes in atrial and ventricular ERP (expressed as a percentage of the baseline values) are shown in Fig 5. The prolongation of ERP showed reverse usedependency at BCLs between 300 to $200 \mathrm{~ms}$ in the atrium, as well as in the ventricle, in the baseline state without vagal stimulation. However, further shortening of the BCL to $150 \mathrm{~ms}$ led to prolongation of atrial ERP. Ventricular ERP was not determined at a BCL of $150 \mathrm{~ms}$. Prolongation of ERP with NIP-142 was greater in the atrium than in the ventricle ( $12 \pm 3 \%$ vs $3 \pm 1 \%$, BCL $300 \mathrm{~ms}, \mathrm{p}<0.05)$. NIP- 142 also significantly prolonged 1:1 SA, 1:1 AV and AH intervals. In contrast, NIP-142 did not change the intraatrial and interatrial CTs, or HV interval.

NIP-142 significantly prolonged atrial ERP at a BCL of $200 \mathrm{~ms}$ during vagal stimulation from $70 \pm 8$ to $121 \pm 11 \mathrm{~ms}$ $(\mathrm{p}<0.01)$. Prolongation of ERP with NIP-142 was greater in the presence of vagal stimulation than in the control state ( $79 \pm 15 \%$ vs $10 \pm 4 \%$, at BCL $200 \mathrm{~ms}, \mathrm{p}<0.05)$.

\section{In Vitro Experiments}

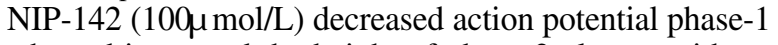
notch, and increased the height of phase-2 plateau without changes in duration or maximal upstroke velocity of the atrial action potential in the control state (Fig 6, Table 2). Carbachol $(0.3 \mu \mathrm{mol} / \mathrm{L})$ significantly shortened APDs at 20, 50 and $90 \%$ of repolarization, and the shortening was attenuated by NIP-142 in a concentration dependent manner (Fig 7, Table 3).

\section{Discussion}

The major findings of the present study are as follows. First, NIP-142 terminated both AF induced under vagal stimulation and AFL caused by macro-reentry in dogs. Second, NIP-142 prolonged atrial ERP with a unique ratedependent property and 1:1 SA interval. This compound prolonged ventricular ERP, but the change was smaller as compared with atrial ERP. Third, NIP-142 did not affect 

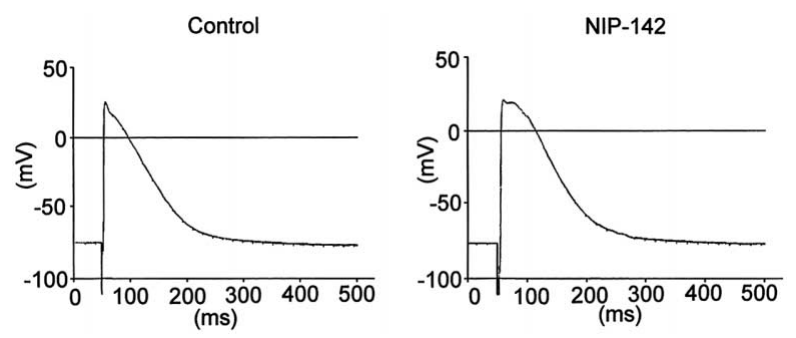

Fig 6. A representative action potential recorded at a stimulation frequency of $1 \mathrm{~Hz}$. NIP-142 (100 $\mathrm{mol} / \mathrm{L})$ decreased the action potential phase-1 notch and increased the height of the phase-2 plateau without a change in action potential duration at $90 \%$ of repolarization.

Table 2 Effects of NIP-142 on Action Potential Parameters of Canine Atrial Muscle

\begin{tabular}{lcccc}
\hline \hline & APD20 $(\mathrm{ms})$ & APD50 $(\mathrm{ms})$ & APD90 $(\mathrm{ms})$ & dV/dt $\max (\mathrm{V} / \mathrm{s})$ \\
\hline Control & $30 \pm 4$ & $70 \pm 3$ & $154 \pm 5$ & $207 \pm 27$ \\
NIP-142 $(\mathrm{\mu} \mathrm{mol} / \mathrm{L})$ & $30 \pm 4$ & $68 \pm 3$ & $152 \pm 4$ & $205 \pm 35$ \\
1 & $29 \pm 4$ & $69 \pm 2$ & $158 \pm 3$ & $198 \pm 30$ \\
10 & $29 \pm 5$ & $69 \pm 6$ & $155 \pm 10$ & $190 \pm 17$ \\
100 & & & & \\
\hline
\end{tabular}

Data expressed as mean values \pm SEM. APD20, APD50 and APD90, action potential duration at 20, 50 and $90 \%$ of repolarization level, respectively (stimulation frequency of $1 \mathrm{~Hz}$ ); $d V / d t$ max, the maximal upstroke velocity of action potential. $p$ value was not significant for each concentration vs control.
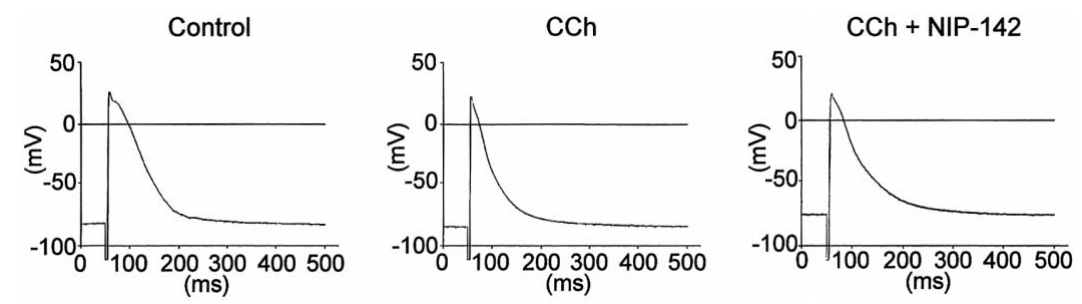

Fig 7. Representative results of effects of carbachol $(\mathrm{CCh}, 0.3 \mu \mathrm{mol} / \mathrm{L})$ and additional NIP-142 $(100 \mu \mathrm{mol} / \mathrm{L})$ on action potential of the canine atrium. Carbachol-induced shortening of action potential duration was reversed with NIP-142 (right panel).

Table 3 Effects of NIP-142 on Action Potential Parameters of Canine Atrial Muscle Pretreated With Carbachol

\begin{tabular}{|c|c|c|c|c|}
\hline & $A P D_{20}(\mathrm{~ms})$ & $A P D 50(m s)$ & $A P D 90(m s)$ & $d V / d t \max (V / s)$ \\
\hline Control & $28 \pm 4$ & $69 \pm 5$ & $147 \pm 5$ & $239 \pm 12$ \\
\hline 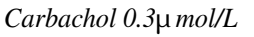 & $14 \pm 2 * *$ & $40 \pm 5 * *$ & $116 \pm 7 *$ & $261 \pm 10$ \\
\hline \multicolumn{5}{|l|}{$\begin{array}{l}\text { Carbachol } 0.3 \mu \mathrm{mol} / \mathrm{L} \\
\quad+N I P-142(\mu \mathrm{mol} / \mathrm{L})\end{array}$} \\
\hline 1 & $14 \pm 2$ & $39 \pm 5$ & $114 \pm 8$ & $271 \pm 14$ \\
\hline 10 & $14 \pm 2$ & $41 \pm 6$ & $121 \pm 10$ & $258 \pm 21$ \\
\hline 100 & $17 \pm 3$ & $51 \pm 7 \dagger$ & $141 \pm 9 \dagger \dagger$ & $222 \pm 31$ \\
\hline
\end{tabular}

Data expressed as mean values \pm SEM. Abbreviations as in Table $2 .{ }^{*} p<0.05,{ }^{*} p<0.001$ vs control; ${ }^{\dagger} p<0.01,{ }^{\dagger} p<0.001$ vs carbachol $0.3 \mu \mathrm{mol} / \mathrm{L}$.

either atrial $\mathrm{CT}$ or $\mathrm{HV}$ intervals, but prolonged both the $\mathrm{AH}$ and 1:1 AV intervals. Fourth, NIP-142 decreased the action potential phase- 1 notch and increased the height of phase- 2 plateau without a change in the APD in the baseline condition. This compound attenuated carbachol induced shortening of the APD in a concentration dependent manner. These findings strongly suggest that this investigational drug has a class III antiarrhythmic effect that is different from other class III antiarrhythmic drugs.

\section{Effects of NIP-142 on the Vagally Induced AF Model}

Based on our preliminary (unpublished) data of the blocking effect of NIP-142 on IK,ACh, we determined whether NIP-142 could terminate vagally induced AF in the dog, and as expected, it effectively terminated AF in $83 \%$ of dogs. Class III drugs with a selective IKr blocking effect, including d-sotalol ${ }^{8}$ dofetilide 9 and nifekalant (MS-551), terminated vagally induced $\mathrm{AF}$ in $87.5 \%, 50 \%$ and $75 \%$ of dogs, respectively. Other class III drugs that suppress both IKr and the slow component of the delayed rectifier current $(\mathrm{Ks})$, such as azimilide ${ }^{9}$ and ambasilide 8 also terminated vagally induced $\mathrm{AF}$ in $93 \%$ and $100 \%$ of dogs, respectively. NIP-142 was as effective as these class III drugs in terminating vagally induced canine AF.

The prolongation of atrial ERP with NIP-142 was greater in the presence of vagal stimulation than in the control state, possibly because of its blocking effect on $I \mathrm{~K}, \mathrm{ACh}$. The effect of class III antiarrhythmic drugs on vagally induced shortening of the atrial ERP differs from drug to drug. Dsotalol and ambasilide have greater effects on atrial ERP in 
the presence of vagal stimulation, 8,10 whereas azimilide does so in the absence of vagal stimulation. In contrast, dofetilide has an almost similar effect on atrial ERP in the presence and in the absence of vagal stimulation? These different results on atrial ERP under vagal stimulation are possibly dependent on different blocking effects on potassium currents. Ambasilide ${ }^{11}$ and dl-sotalol ${ }^{12}$ inhibit $I K, A C h$ in guinea pig atria, but d-sotalol ${ }^{11}$ does not. The effects of dofetilide and azimilide on $\mathrm{IK}, \mathrm{ACh}$ are not known yet.

Preliminary ligand analysis revealed that NIP-142 did not directly bind to muscarinic receptors (unpublished data). The effectiveness of NIP-142 in terminating and preventing vagally induced $\mathrm{AF}$ and its greater effect on ERP under vagal stimulation are consistent with suppression of $I \mathrm{~K}, \mathrm{ACh}$. This was also supported by our in vitro experiment in which NIP-142 attenuated carbachol induced shortening of the APD in a concentration dependent manner.

\section{Effects of NIP-142 on the AFL With Anatomical Obstacle Model}

Based on the efficacy of NIP-142 for vagally induced $\mathrm{AF}$, we also tested whether this new compound could terminate AFL induced after placing an anatomical obstacle. This AFL model did not depend on vagal stimulation. Unexpectedly, AFL was terminated without any appreciable increases in flutter CL and was not inducible after the injection of NIP-142. Class III and Ic drugs are effective in terminating canine AFL caused by reentry 13 Prolongation of flutter CL is less when treated with class III drugs as compared with class Ic drugs; this finding suggests that flutter CL depends on conduction velocity but not on refractoriness in the anatomical obstacle model of reentry!13,14 The present result is consistent with a class III antiarrhythmic effect of NIP-142. Before termination of AFL with NIP142, AFL degenerated into AF in 2 dogs as is sometimes seen with class III drugs 15,16 Selective IKr blockers, dsotalol $^{14}$ and E-4031, ${ }^{13}$ have $86 \%$ and $100 \%$ termination of AFL, and $29 \%$ and $100 \%$ of prevention of AFL, respectively, in the canine model with intercaval crush. Another new class III drug, azimilide, which blocks both $I \mathrm{Kr}$ and $I \mathrm{Ks}$, terminated AFL and suppressed re-initiation of AFL in $100 \%$ of dogs in a sterile pericarditis model ${ }^{17}$

The plasma concentration of NIP-142 just after termination of AFL was $1.7 \mu \mathrm{g} / \mathrm{ml}$ or $3.9 \mu \mathrm{mol} / \mathrm{L}$. In vitro data from the carbachol-treated atrial muscle suggest that this concentration of NIP-142 would produce little effect on atrial ERP even in the presence of high vagal tone. NIP-142 might be deactivated rapidly in vivo; but this needs to be clarified.

\section{Electrophysiological Effects of NIP-142}

The mechanism of NIP-142's ability to terminate and prevent AFL caused by macroreentry can be explained by its effect on ionic currents other than $\mathrm{IK}, \mathrm{ACh}$. The prolongation of atrial ERP by NIP-142 decreased as the BCL shortened from 300 to $200 \mathrm{~ms}$. However, the prolongation by NIP-142 became greater at the shortest BCL of $150 \mathrm{~ms}$ (Fig 5) and this was reflected in the significant increase in the 1:1 SA interval. These results indicate that NIP-142 has unique use dependency for atrial ERP as compared with many other class III antiarrhythmic drugs, 8,9 The mechanism of the biphasic effect of NIP-142 on the use dependency for atrial ERP is not clarified yet, but might involve frequency dependent changes in the balance of action on the inward currents such as the sodium current $\left(I_{\mathrm{Na}}\right)$ and $I \mathrm{Ca}$ vs the outward currents such as $I \mathrm{~K}, \mathrm{ACh}$, the transient outward current
(Ito), the ultrarapid component of delayed rectifier current (IKur), IKr and IKs.

A previous study showed that NIP-142 prolonged guinea pig atrial but not ventricular ERP4 In contrast, in the present study NIP-142 slightly prolonged both atrial and ventricular ERP. This difference between the guinea pig and dog could be attributable to a species-specific distribution of cardiac ionic currents. The in vitro study showed that NIP142 did not change the APD of atrial cells in the absence of carbachol. The discrepancy between the effects of NIP-142 on atrial ERP in vivo and the lack of a change in atrial APD in vitro may be explained by the presence of the intact vagi in the in vivo study. The resting basal vagal tone could have some effects on atrial ERP in vivo through $I \mathrm{~K}, \mathrm{ACh}$.

In the present study we observed a loss of phase-1 notch, an increase in the height of the plateau and no change in the APD at a stimulation frequency of $1 \mathrm{~Hz}$. Mathematical model analysis ${ }^{18}$ suggests that the changes in action potential configuration induced with NIP-142 could be explained through suppression of $I_{\text {to }}$ and $I$ Kur. The prolongation of ERP by NIP-142 was greater in the atrium than in the ventricle (Table 1, Fig 5), a finding suggestive of suppression of canine IKur, and suppression of Ito with NIP-142 might account for the slight increase in the ventricular ERP. The effects of NIP-142 on ionic currents have been studied by several investigators. Matsuda et al studied the effect of NIP142 on cloned human cardiac K channel Kv 1.5 (hKv1.5) using whole-cell voltage-clamp methods 19 The hKv1.5 channel is the molecular identity of the IKur in the human heart. NIP-142 inhibited the hKv1.5 current in a concentration-dependent manner but independent of frequency. Seki et al evaluated the effect of NIP-141 (hydrochloride of NIP142) on human atrial myocytes using whole-cell voltageclamp methods ${ }^{20}$ and found that NIP-141 inhibited both Ito and $I$ Kur in a dose-dependent manner. These findings are consistent with ours.

Significant prolongation of the AH interval and 1:1 AV interval with NIP-142 could be caused by suppression of ICa5 In the clinical setting, suppression of the AV node through inhibition of $I_{\mathrm{Ca}}$ is useful for slowing the ventricular response during atrial tachyarrhythmias. In the present study, $\mathrm{Na}$ dependent conduction (ie, inter- and intra-atrial conduction) was not affected by NIP-142 at a pacing cycle length of $150 \mathrm{~ms}$. Furthermore, the flutter CL of AFL induced with an anatomical obstacle, which is dependent on the circuit length and the conduction velocity, was not prolonged by NIP-142. These suggest that termination of AF and AFL by NIP-142 is not attributable to suppression of INa.

\section{Study Limitations}

First, experimental efficacy can not be directly extrapolated to the clinical setting. There are some differences in atrial electrophysiological properties between species; IKur in the dog has different properties from that in the human20,22 Furthermore, the mechanisms of AF and AFL in the present study might not be identical to those of clinical $\mathrm{AF}$ and AFL. The properties of AF induced by vagal stimulation in dogs could be different from those in the diseased, dilated atria seen in chronic AF. However, this canine model of AF may resemble paroxysmal AF occurring under increased vagal tone in selected patients with relatively normal atria23,24 Second, the dose-response effects of NIP142 on cardiac electrophysiologic variables were not determined. Third, NIP-142 reversed carbachol induced short- 
ening of APD, suggesting inhibition of $I_{\mathrm{K}, \mathrm{ACh}}$, but direct determination of ionic currents was not performed. Finally, action potential properties were determined only at a stimulation CL of $1 \mathrm{~s}$, so combinations at shorter CL could have revealed more detailed rate dependent effects of NIP-142.

\section{Conclusion}

Although the present study was limited for the reasons just oulined, NIP-142 is a promising, new antiarrhythmic drug with a unique rate dependent effect on atrial ERP. It has less effect on ventricular refractoriness compared with the atrium and suppresses $\mathrm{AH}$ conduction, suggesting a potential effectiveness in treating clinical AF and AFL with low risk of ventricular proarrhythmia.

\section{References}

1. Roden DM, Hoffman BF. Action potential prolongation and induction of abnormal automaticity by low quinidine concentrations in canine Purkinje fibers: Relationship to potassium and cycle length. Circ Res 1985; 56: 857-867.

2. Hondeghem LM, Snyders DJ. Class III antiarrhythmic agents have a lot of potential but a long way to go: Reduced effectiveness and dangers of reverse use dependence. Circulation 1990; 81: 686-690.

3. Fujikura N, Yokoyama T, Hashimoto N, Yamashita T, Tsuruzoe N. Antiarrhythmic and hemodynamic effects of a novel benzopyran derivative, NIP-142, in anesthetized animals (abstract). Jpn J Pharmacol 1999; 79(Suppl I): 179 .

4. Yamashita T, Matsuda T, Itokawa M, Tanaka H, Shigenobu K, Tsuruzoe N. A novel benzopyran derivative NIP-142 has unique atrium- and sinus-selective antiarrhythmic effects in vitro (abstract). Jpn J Phamacol 1999; 79(suppl I): 176.

5. Matsuda T, Masumiya H, Saito T, Tanaka H, Shigenobu K, Yamashita T, et al. NIP-142, a novel benzopyran derivative: Electrophysiological study on the mechanisms of bradycardiac effects (abstract). Jpn J Phamacol 1999; 79(Suppl I): 178.

6. Hayashi H, Fujiki A, Tani M, Usui M, Inoue H. Different effects of class Ic and III antiarrhythmic drugs on vagotonic atrial fibrillation in the canine heart. J Cardiovasc Pharmacol 1998; 31: 101-107.

7. Yamashita T, Inoue H, Nozaki A, Kuo T, Usui M, Sugimoto T. Role of anisotropy in determining the selective action of antiarrhythmics in atrial flutter in the dog. Cardiovasc Res 1992; 26: 244-249.

8. Wang J, Feng J, Nattel S. Class III antiarrhythmic drug action in experimental atrial fibrillation: Differences in reverse use dependence effectiveness between $d$-sotalol and the new antiarrhythmic drug ambasilide. Circulation 1994; 90: 2032-2040.

9. Nattel S, Liu L, St-Georges D. Effects of the novel antiarrhythmic agent azimilide on experimental atrial fibrillation and atrial electrophysiologic properties. Cardiovasc Res 1998; 37: 627-635.

10. Wang J, Bourne GW, Wang Z, Villemaire C, Talajic M, Nattel S. Comparative mechanisms of antiarrhythmic drug action in experimental atrial fibrillation: Importance of use-dependent effects on refractoriness. Circulation 1993; 88: 1030-1044.

11. Zaza A, Malfatto G, Schwartz PJ. Effects on atrial repolarization of the interaction between $\mathrm{K}^{+}$channel blockers and muscarinic receptor stimulation. J Pharmacol Exp Ther 1995; 273: 1095-1104.

12. Mori K, Hara Y, Saito T, Masuda Y, Nakaya H. Anticholinergic effects of class III antiarrhythmic drugs in guinea pig atrial cells: Different molecular mechanisms. Circulation 1995; 91: 2834-2843.

13. Inoue $\mathrm{H}$, Yamashita $\mathrm{T}$, Nozaki A, Sugimoto $\mathrm{T}$. Effects of antiarrhythmic drugs on canine atrial flutter due to reentry: Role of prolongation of refractory period and depression of conduction to excitable gap. J Am Coll Cardiol 1991; 18: 1098-1104.

14. Spinelli W, Hoffman BF. Mechanisms of termination of reentrant atrial arrhythmias by class I and class III antiarrhythmic agents. Circ Res 1989; 65: 1565-1579.

15. Guo GBF, Ellenbogen KA, Wood MA, Stambler BS. Conversion of atrial flutter by ibutilide is associated with increased atrial cycle length variability. J Am Coll Cardiol 1996; 27: 1083-1089.

16. Stambler BS, Wood MA, Ellenbogen KA. Antiarrhythmic actions of intravenous ibutilide compared with procainamide during human atrial flutter and fibrillation: Electrophysiological determinants of enhanced conversion efficacy. Circulation 1997; 96: 4298-4306.

17. Restivo M, Hegazy M, Caref EB, Avitable MJ, Assadi MA, elHamami M, et al. Effects of azimilide dihydrochloride on circus movement atrial flutter in the canine sterile pericarditis model. $J$ Cardiovasc Electrophysiol 1996; 7: 612-624.

18. Courtemanche M, Ramirez RJ, Nattel S. Ionic targets for drug therapy and atrial fibrillation-induced electrical remodeling: Insights from a mathematical model. Cardiovasc Res 1999; 42: 477-489.

19. Matsuda T, Masumiya H, Tanaka N, Yamashita T, Tsuruzoe N, Tanaka H, et al. Inhibition by a novel anti-arrhythmic agent, NIP-142, of cloned human cardiac $\mathrm{K}^{+}$channel Kv1.5 current. Life Science 2001; 68: 2017-2024.

20. Seki A, Hagiwara N, Kasanuki H. Effects of NIP-141 on K currents in human atrial myocytes. J Cardiovsc Pharmacol (in press).

21. Feng J, Wible B, Li GR, Wang Z, Nattel S. Antisense oligodeoxynucleotides directed against Kv1.5 mRNA specifically inhibit ultrarapid delayed rectifier $\mathrm{K}+$ current in cultured adult human atrial myocytes. Circ Res 1997; 80: 572-579.

22. Yue L, Feng J, Li GR, Nattel S. Characterization of an ultrarapid delayed rectifier potassium channel involved in canine atrial repolarization. J Physiol (Lond) 1996; 496: 647-662.

23. Coumel P. Paroxysmal atrial fibrillation: A disorder of autonomic tone? Eur Heart J 1994; 15(Suppl A): 9-16.

24. Yamashita T, Murakawa Y, Sezaki K, Inoue M, Hayami N, Shuzui Y, et al. Circadian variation of paroxysmal atrial fibrillation. Circulation 1997; 96: $1537-1541$. 